\title{
A case of neurofibromatosis complicated by medulloblastoma, neurogenic sarcoma, and radiation-induced carcinoma of thyroid
}

\author{
A. G. L. CORKILL ${ }^{1}$ AND C. F. ROSS \\ From the South-East Metropolitan Regional Neurosurgical Unit, Brook General Hospital, and \\ North-West Surrey Group Pathology Laboratory, St. Peter's Hospital, Chertsey
}

Von Recklinghausen described the features of multiple neurofibromatosis in 1882 , though Willis (1962) points out that there had been several earlier descriptions of the condition including a monograph by Smith (1849). Brooks and Lehman (1924) drew attention to the skeletal abnormalities in this condition. Crowe, Schull, and Neel (1956) made a clinical, pathological, and genetic study of 223 cases and Rosman and Pearce (1967) have correlated histological abnormalities with the associated intellectual deficit. Malignant change in the affected nerves is well known and was reviewed by Stewart and Copeland in 1931. Clark (1955) pointed out the increased incidence of carcinoma of the thyroid following irradiation of the neck for non-thyroid conditions, and Winship and Rosvoll (1961) estimated that $80 \%$ of a series of 562 cases of thyroid cancer in children had received radiotherapy. Pifer and Hempelmann (1964) found a similar association and reviewed the literature. The present case manifested two forms of spontaneous and one form of induced neoplasia.

\section{CASE REPORT}

An 8-year-old boy was admitted to a neurosurgical unit in October 1957, with a two-month history of tendency to veer to the left when walking, and holding his head to the left side. Two days before admission he had suffered from headache, diplopia, anorexia, and morning vomiting. A marked feature of the headache was that it was relieved by lying down. His symptoms were rapidly progressive. There were no significant antecedent illnesses. The paternal grandfather suffered from lumps covering his body and he died when these, it was said, had 'gone to his spine'. His father, though alive and in good health, was similarly affected, and occasional subcutaneous lumps had been removed for pain. The patient was an only child, though his parents would have liked more children, and it is likely that the father was sub-

'Present address: Department of Neurosurgery, Government Hospital, Tripoli/Libya. fertile. Reduced fertility is not uncommon in neurofibromatosis (Crowe et al., 1956).

Examination revealed bilateral papilloedema, nystagmus on lateral gaze to the right, and diplopia on looking upwards. A right-sided facial weakness was present affecting upper and lower face equally. Generalized hypotonia and motor ataxia with dysmetria and intention tremor affected all four limbs, with relative sparing of the left side. The left lower abdominal reflex was absent, and the left plantar reflex equivocal, the right being frankly flexor. There was no sensory loss. Lumbar puncture done at the referring hospital one week previously had been normal in every respect. Plain radiographs of the skull and chest were normal. Ventriculography, however, showed symmetrical hydrocephalus of the third and lateral ventricles with displacement of the posterior end of the third ventricle of the aqueduct and of the fourth ventricle by a right-sided posterior fossa mass. Exploration revealed a gelatinous, yellow tumour lying in the antero-medial portion of the right cerebellar hemisphere. As much as possible was removed and histological examination was reported as showing features of a medulloblastoma, although the degree of necrosis present was thought to be somewhat unusual. Post-operatively he had a residual tendency to hold his head to the left. Because of the persisting contralateral cerebellar signs and the nature of the tumour, he was given radiotherapy. A dose of 2,975 $\mathrm{r}$ was given, which was well tolerated apart from a temporary leucopenia of 2,400 white cells/c. mm. It was estimated that the thyroid gland received a dose of $800 \mathrm{r}$ during the course of treatment. He remained well, attended school, and apart from a practically isolated disability, a dyslexia, he developed normally and got a job.

In 1966, at the age of 17 , he was found at routine follow-up to have pain around the lower aspect of the right scapula which radiated to the right upper limb. The subcutaneous swellings and café-au-lait spots of Von Recklinghausen's disease were evident and it was noticed that he had a prominent, firm thyroid gland. In addition, he had a partial right Horner's syndrome, the cutaneous component of the syndrome being absent, but the ptosis and miosis being marked. There was also weakness and wasting of the intrinsic muscles of both hands, the right side being more marked than the left. There was hyper- 
reflexia of the tendon jerks in the right lower limb, bilateral ankle clonus, and extensor plantar responses. Radiographs of the cervical spine showed an increase in size of the exit foramina on the right side, and myelography showed a partial block at this level, maximal at C6. Laminectomy failed to reveal any extradural lesion, but a large fusiform arachnoid cyst was found stretching the rootlets from $\mathrm{C5}$ to $\mathrm{C} 2$. Opening of the cyst was followed by pulsation being seen for the first time during the operation.

Uneventful recovery followed, with loss of ankle clonus but retention of other neurological deficits. Radiographs of the chest had shown a large mass lying in the posterior mediastinum, so thoracotomy was performed through the fourth intercostal space on the right on 5 December 1967. A mass, $5 \mathrm{~cm}$ in diameter, was found situated in the apex of the chest. It was lobulated and adherent to the first and second ribs and the intervening space. Other masses of similar dimensions were found scattered throughout the right side of the chest in relationship to most of the important structures. The larger of these were removed. Frozen sections studied during operation suggested neurofibrosarcoma. Paraffin section showed giant forms and mitoses, but definite malignant change was not thought to be present. The possibility of radiotherapy was entertained but rejected. He made an uneventful post-operative recovery.

A further admission to hospital occurred five months later as a result of the development of a mobile subcutaneous mass in the region of the left scapula. There was no change in his neurological status and the tumour was removed. Histology showed it to be an oedematous neurofibroma.

His fourth and final admission occurred two months later, on 9 October 1967, when he was brought to the outpatient department in exceedingly severe pain affecting the right arm. This pain made it impossible to dress or wash him, and was relieved only by the continual adoption of the prone position. Examination revealed a persistent partial right Horner's syndrome, weakness and wasting of the small muscles of both hands and flexor muscles of both forearms, and impairment of all forms of sensation on the ulnar border of the right forearm and hand. There was impairment of cutaneous sensation below the angle of Louis, with bilateral extensor plantar responses and loss of joint position sense in the right lower limb. Myelography revealed a block at the T1/C7 junction, the appearances being consistent with a neurofibroma. Laminectomy, however, failed to reveal this. The bone was extremely vascular, and there was a posterior projection of a bar of soft, vascular bone at the relevant level consistent with the myelographic appearances. So profuse had the bleeding been on exposure that biopsy of the bone was not felt justified. Post-operatively, his neurological condition was unchanged, but then a severe paraparesis with retention of urine occurred, and a new dense level of sensory loss at T6/7. Re-screening and tomography were undertaken and demonstrated collapse of the body of T4 vertebra. On supportive measures he improved, and arrangements were made for transfer to an orthopaedic unit for consideration for anterior fusion. Within five days of arrival, however, he developed progressive respiratory failure, having apparently lost the use of his intercostal muscles, an died on 25 November 1967.

\section{PATHOLOGY}

Necropsy was performed 49 hours after death. Externall the body was that of a thin adolescent male wit numerous café-au-lait patches but no detectable ski行 tumours. Well healed surgical scars were present various situations and a defect could be felt through the scalp over the occiput. The lower limbs were wasted an there was bilateral pes cavus.

Internally, no recurrence of tumour was found withio the skull, but a haemorrhagic metastasis $2 \mathrm{~cm}$ in diamete was present in the right parietal lobe just behind an midway along the central sulcus. Behind it was a cystie cavity $15 \times 10 \times 10 \mathrm{~mm}$ traversed by some filmy bands? with two smaller cysts close by. Throughout the cerebrung were scattered pin-point-sized haemorrhagic foci, some. of which were brownish. There were no tumours ont cranial nerves and the rest of the intracranial nervous system was normal. The spine showed haemorrhag: growth involving all the cervical and six upper thorace vertebrae, with complete collapse of T4 and lowero cervical bodies and infiltration of the subcutaneous tissues and spinal muscles. Discrete metastases were seen vertebra L1. A few small grey tumours were seen posterior nerve rami among the spinal muscles. \$h spinal cord in the lower cervical and upper thoracic regh was enveloped in a thick mass of firm grey haemorrhagigs growth both inside and outside the partly destroyed dura. This was more evident on the right where it wașu to $15 \mathrm{~mm}$ in thickness and invading muscles. Much boun clot was seen beneath the dura throughout the cord The latter was largely necrotic and haemorrhigf (infarcted) from C7 to L2 but appeared intact above anf $\mathbb{P}$ below these points. In the neck were numerous firm glistening partly translucent nerve tumours deep among the muscles, up to $4 \mathrm{~cm}$ in diameter. The largest showed central necrosis and haemorrhage. The thyroid was net enlarged but several small pale foci, the largest $8 \mathrm{~mm}$ diameter, were seen in each lobe. No malignant lymph nodes were encountered. The chest contained no frge fluid but there were old adhesions on the right. A large tumour mass, similar to those described above, measuring $10 \times 5 \times 4 \mathrm{~cm}$ was present at the apex of the rige pleural cavity, which on slicing showed necrosis and haemorrhage where it was invading the pleur. Numerous thickened nerves were seen throughout the mediastinum, some of them forming tumourous expar sions several centimetres in diameter. A similar condition was seen in the brachial plexuses and a nodule $2.5 \mathrm{~cm}$. diameter was present in the left median nerve in the axilla. The inner end of the right first rib contained tumour. The heart and thymus were normal. The lungs contained numerous haemorrhagic nodules up to $15 \mathrm{~m}$ it in diameter, predominantly subpleural in distributiog and the air passages contained frothy sanguineous . oedema fluid. The abdomen showed numerous tumours, both near the spine and peripherally, including the sympathetic chain. The largest was projecting into bof 4

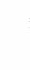


not invading the left psoas muscle. It measured $8 \times 6 \times$ $4 \mathrm{~cm}$ and was producing a concavity in the side of the 1 fourth lumbar vertebral body. Another large one was present on the right femoral nerve. Other nerves showed thickening but no actual tumour nodules. Some were oedematous and haemorrhagic. Apart from the above no other disease was seen, all the viscera being normal except for some cystitis and a septic spleen.

Histological examination The nerve tumours showed a variety of appearances from a quite benign structure (Fig. 1), through early malignant change (Fig. 2), to frankly anaplastic growth (Fig. 3). A feature of the latter was its extreme vascularity, in places of almost angiosarcomatous structure. This type of growth was destroying vertebrae and infiltrating muscle and connective tissues in the neck and involving the spinal cord. Metastases of similar structure were seen in the lungs, brain and vertebra L1. Some nerves showed marked oedema, infiltration with lymphocytes and diffuse neurofibromatous change (Fig. 4). The cerebrum showed minute foci of perivascular softening and infarction, thought to be due to tumour emboli, and also foci of venous malformation. The cerebral cyst had a membraneous glial lining, which became detached during processing. The thyroid contained a focus of carcinoma which was partly papillary, partly follicular and partly anaplastic (Fig. 5), and metastases from this were present in the partly benign, partly malignant nerve tumour mass at the apex of the right hemithorax (Fig. 6). The appearance suggested that these were of lymphatic origin rather than haematogenous and no similar metastases were found elsewhere.

\section{DISCUSSION}

The points of interest in this case are neurological and pathological. The dyslexia, which was one of the patient's focal and isolated disabilities, might be attributable to a partial left homonymous hemianopia, such as would escape detection in simple confrontation testing. The basis for such a hemianopia might be the focal failure of cortical development recently suggested by Rosman and Pearce (1967) and present in this case as cystic lesions in the right parietal lobe. The partial Horner's syndrome is illustrative of the sub-total recovery from sympathectomy that occurs in the skin, but not apparently of other sympathetically innervated structures.

The pathological features of interest are the two spontaneous neoplastic processes-namely, medulloblastoma of the cerebellum and the multifocal sarcomatous change in the neurofibromas and, in addition, the carcinoma of thyroid. It would seem that the radiation which brought about the cure of the medulloblastoma unfortunately induced malignant change in the thyroid. It was not until at a later date, when the sections of the thyroid had been seen, that the nature of the epithelial structures in

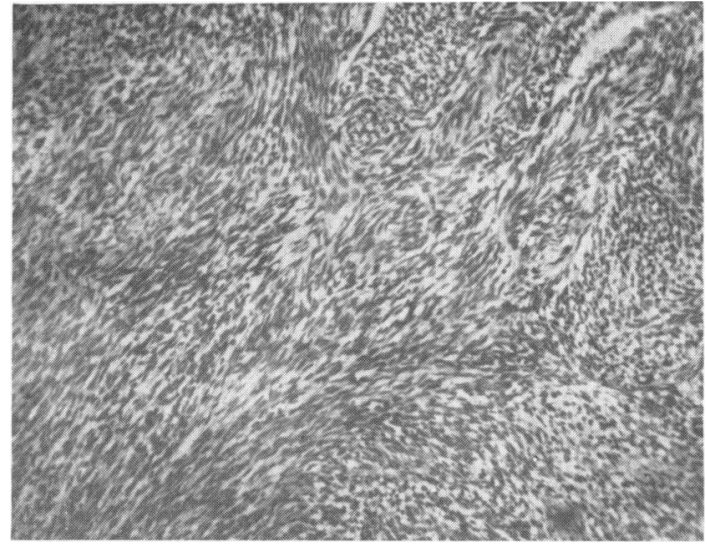

FIG. 1. A nerve tumour of benign structure. Haematoxylin and eosin. $\times 130$.

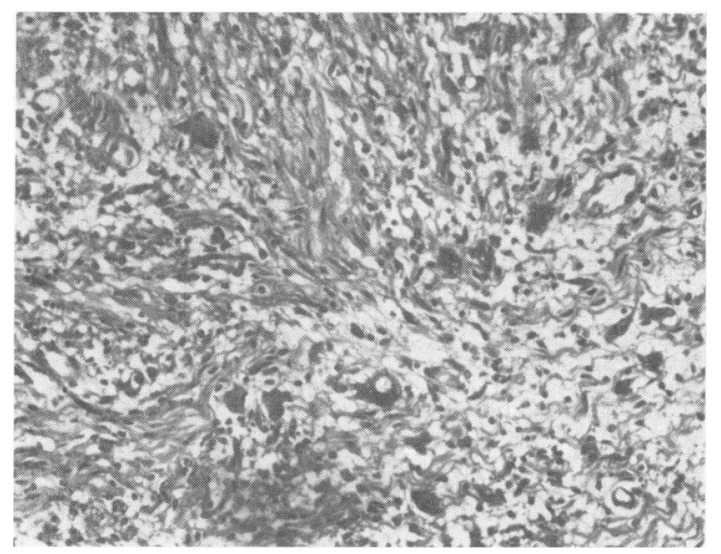

FIG. 2. A nerve tumour with early but definite malignant changes. Haematoxylin and eosin. $\times 130$.

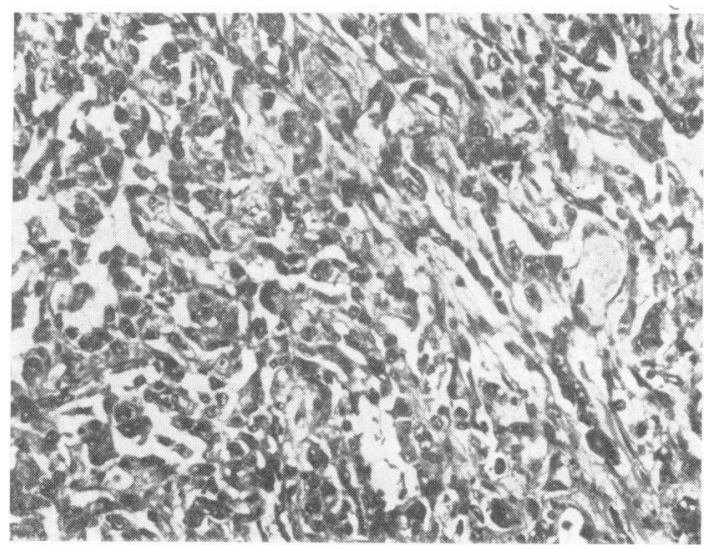

FIG. 3. Frankly anaplastic sarcomatous change in a nerve tumour. Haematoxylin and eosin. $\times 130$. 
the nerve tumour was elucidated. At first it was thought that the appearances might be neuroepitheliomatous, since three of the cases reviewed by Stewart and Copeland (1931) manifested something similar, and Garrè (1892) had described a neuromatous tumour having epithelial elements of adenomatous structure. However, reference to Figs. 5 and 6 demonstrates the similar appearances in thyroid and nerve tumour. Willis (1967) is of the opinion that the reported primary 'neuroepitheliomas' of nerves were probably all secondary to undiscovered primary carcinomas, and agrees with us that the epithelial tumour in the nerve mass at the right apex is metastatic from the thyroid carcinoma (personal communication). It is well known that nerves are resistant to tumour invasion and when this occurs it is by lymphatics (Willis, 1952). Haematogenous dissemination is so rare as to be a curiosity. In the present case, although no malignant lymph nodes were found, small foci of growth in the interstitial tissue of the thyroid were found which could have been due to lymphatic involvement, with consequent spread to the mass at the apex of the right lung.

Von Recklinghausen's disease may be accompanied by other manifestations of disordered growth in other parts of the nervous system and elsewhere, and gliomas have been described on a number of occasions. When the nerve tumours become malignant (in $13 \%$ according to Hosoi, 1931) pleomorphism is usual and in the present case closely mimicked angiosarcoma in parts. The presence of a vascular component to neurofibromatosis is well known and perhaps this is relevant.

\section{SUMMARY}

The 10 years' course of Von Recklinghausen's disease in a young male is described, which was complicated by a medulloblastoma of the cerebellum, multifocal malignant change in the neurofibromas, and radiation-induced thyroid carcinoma with metastatic involvement of one of the sarcomatous nerve tumours.

Our thanks are due to Mr. G. C. Knight, Brook General Hospital, and to Mr. A. G. Apley, Rowley Bristow Orthopaedic Hospital, Pyrford, for access to the patient's records. This case was the subject of a clinicopathological discussion at the Royal Postgraduate Medical School, Hammersmith, London, and we are indebted to Professor C. V. Harrison for the sections of thyroid. We are most grateful to Professor R. A. Willis who confirmed the identity of the thyroid growth and epithelial tumour of the nerve lesion and read the manuscript and to Dr. P. B. Woodyatt, Hammersmith Hospital, London,

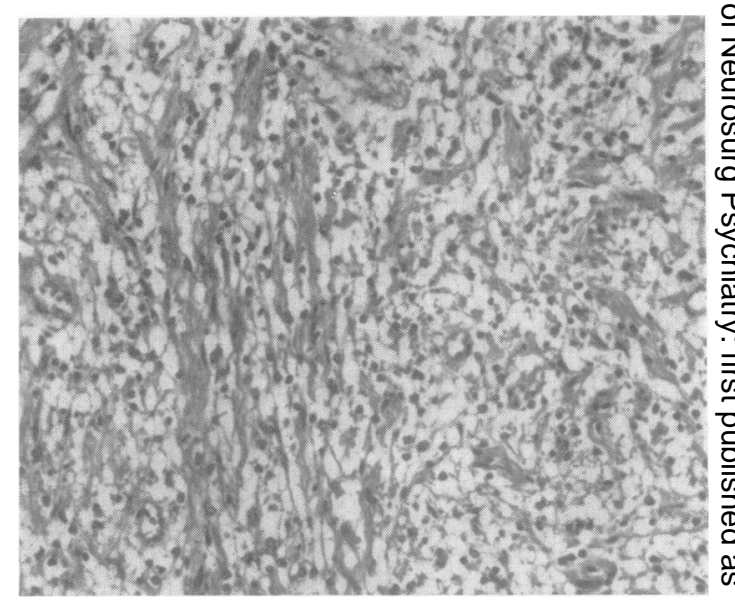

FIG. 4. A nerve tumour showing oedema and lymphocytic $\vec{\circ}$ infiltration. Haematoxylin and eosin. $\times 130$.

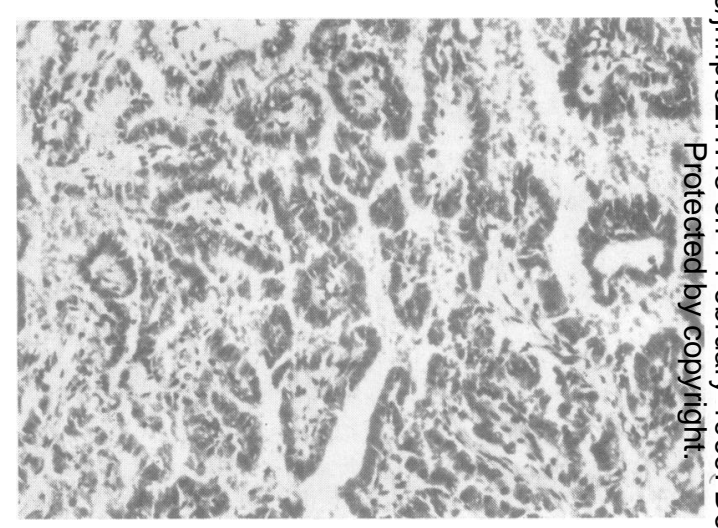

FIG. 5. Thyroid carcinoma. Haematoxylin and eosin. 130.

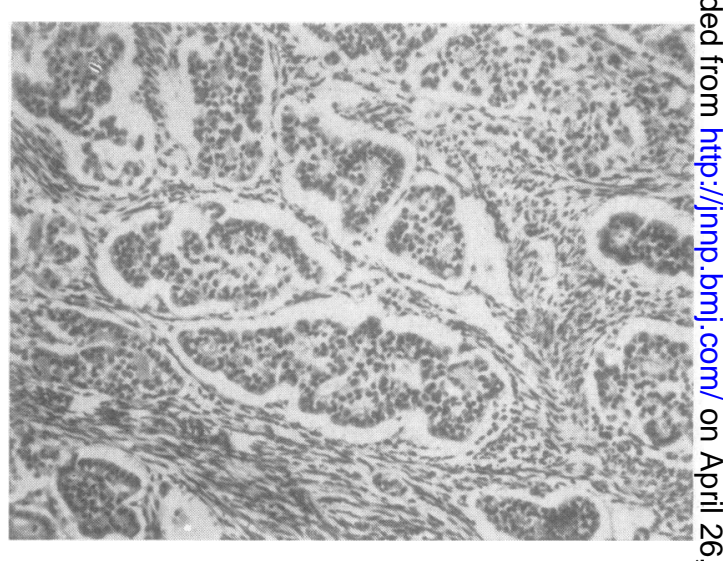

FIG. 6. Metastatic deposit in malignant nerve tumour. Haematoxylin and eosin. $\times 130$. 
for details of the radiotherapy. Requests for reprints should be addressed to C.F.R.

\section{REFERENCES}

Brooks, B., and Lehman, E. P. (1924). The bone changes in Recklinghausen's neurofibromatosis. Surg. Gynec. Obstet., 38, 587-595.

Clark, D. E. (1955). Association of irradiation with cancer of the thyroid in children and adolescents. J. Amer. med. Ass., 159, 1007-1009.

Crowe, F. W., Schull, W. J., and Neel, J. V. (1956). A Clinical, Pathological and Genetic Study of Multiple Neurofibromatosis. Thomas, Springfield, Illinois.

Garrè, C. (1892). Ueber sekundär maligne Neurome. Beitr. klin. Chir., 9, 465-495.

Hosoi, K. (1931). Multiple neurofibromatosis (von Recklinghausen's disease) with special reference to malignant transformation. Arch. Surg., 22, 258-281.

Pifer, J. W., and Hempelmann, L. H. (1964). Radiation-induced thyroid carcinoma. Ann. N.Y. Acad. Sci., 114, 838-848.
Recklinghausen, F. von. (1882). Ueber die multiplen Fibrome der Haut und ihre Beziehung zu den multiplen Neuromen. Hirschwald, Berlin.

Rosman, N. P., and Pearce, J. (1967). The brain in multiple neurofibromatosis (von Recklinghausen's disease): a suggested neuropathological basis for the associated mental defect. Brain, 90, 829-838.

Smith, R. W. (1849). Treatise on the Pathology, Diagnosis and Treatment of Neuroma. Hodges and Smith, Dublin.

Stewart, F. W., and Copeland, M. M. (1931). Neurogenic sarcoma. Amer. J. Cancer, 15, 1235-1320.

Willis, R. A. (1952). The Spread of Tumours in the Human Body, 2nd ed., p. 124. Butterworth, London.

- (1962). The Borderland of Embryology and Pathology, 2nd ed., p. 365. Butterworth, London.

- (1967). Pathology of Tumours, 4th ed., p. 854. Butterworth, London.

Winship, T., and Rosvoll, R. V. (1961). Childhood thyroid carcinoma. Cancer (N.Y.), 14, 734-743.

\section{The December 1968 Issue}

\section{THE DECEMBER 1968 ISSUE CONTAINS THE FOLLOWING PAPERS}

An hereditary motor neurone disease with progressive denervation of muscle in the mouse: the mutant 'wobbler' L. W. DUCHEN and SABINA J. STRICH (With an Appendix by D. S. FALCONER)

Thalidomide neuropathy: a clinical, electrophysiological, and histological follow-up study PAMELA M. FULLERTON and D. J. O'SULLIVAN

Globular neuropathy. A disorder of axons and Schwann cells A. D. DAYAN, G. S. GRAVESON, P. K. ROBINSON, and M. A. WOODHOUSE

Neurological effects of glutethimide DAVID C. HAAS and A. MARASIGAN

Recruitment order of motor units on voluntary contraction: changes induced by proprioceptive afferent activity LENNART GRIMBY and JAN HANNERZ

Effects of sleep on human reflexes with a double component BHAGWAN SHAHANI

Invasive craniopharyngioma WARREN D. GROVER and LUCY BALIAN RORKE

Central pontine myelinolysis associated with acute haemorrhagic pancreatitis RICHARD J. SHERINS and M. ANTHONY VERITY

Histochemistry of Rathke pouch tumours w. R. TIMPERLEY
Basilar impression and Arnold-Chiari malformation. A study of 66 cases M. CAETANO DE BARROS, W. FARIAS, L. ATAÍDE, and S. LINS

Infarction in the optic nerve CARL ELLENBERGER, JR. and MARTIN G. NETSKY

Surgical management of intracranial Hodgkin's disease T. F. BUCKLEY and F. WARWICK

Fatal hypertensive intracerebral haematomas: a survey of the pathological anatomy of 393 cases ELLA FREYTAG

Biochemical changes after spontaneous subarachnoid haemorrhage. Part III. Coagulation and lysis with special reference to recurrent haemorrhage ANNE H. C. UTTLEY and MONAMY BUCKELL

Malignant cerebral melanoma complicating giant pigmented naevus: a case report L. L. MORRIS and G. DANTA

Early biochemical changes in plasmocid myopathy PAULINE MONRO

Neuromyelitis optica versus subacute necrotic myelitis: Part II. Anatomical study of two cases J. C. ORTIZ DE ZÁRATE, L. TAMAROFF, R. E. P. SICA, and J. A. RODRIGUEZ

Proceedings of the Society of British Neurological Surgeons: 77th Meeting

Book reviews

Copies are still available and may be obtained from the PUBLISHING MANAGER BRITISH MEDICAL ASSOCIATION, TAVISTOCK SQUARE, W.C.1, price 18s. 6D. 